\title{
Cytokine expressions of spinal cord injury treated by neurotropin and nafamostat mesylate
}

\author{
Chao Sun ${ }^{1,2 \#}$, Bo Li ${ }^{1, \#}$, Huiquan Duan ${ }^{1,2 \#}$, Bo Tao ${ }^{1,2 \#}$, Chenxi Zhao ${ }^{1,2}$, Wenxiang Li ${ }^{1,2}$, Yilin Pang ${ }^{1,2}$, \\ Baoyou Fan ${ }^{1,2}$, Shiqing Feng ${ }^{1,2}$
}

${ }^{1}$ Department of Orthopedics, Tianjin Medical University General Hospital, Tianjin, China; ${ }^{2}$ International Science and Technology Cooperation Base of Spinal Cord Injury, Tianjin Key Laboratory of Spine and Spinal Cord, Department of Orthopedics, Tianjin Medical University General Hospital, Tianjin, China; ${ }^{3}$ Department of Orthopedics, Sun Yat-sen Memorial Hospital of Sun Yat-sen University, Guangzhou, China

Contributions: (I) Conception and design: S Feng, C Sun; (II) Administrative support: S Feng; (III) Provision of study materials or patients: S Feng, C Sun; (IV) Collection and assembly of data: C Sun, B Li, H Duan, B Tao; (V) Data analysis and interpretation: C Sun, B Li; (VI) Manuscript writing: All authors; (VII) Final approval of manuscript: All authors.

"These authors contributed equally to this work.

Correspondence to: Shiqing Feng. International Science and Technology Cooperation Base of Spinal Cord Injury, Tianjin Key Laboratory of Spine and Spinal Cord, Department of Orthopedics, Tianjin Medical University General Hospital, 154 Anshan Road, Heping District, Tianjin 300052, China. Email: sqfeng@tmu.edu.cn.

Background: Spinal cord injury (SCI) leads to severe physical disability and sensory dysfunction. Neurotropin (NTP) has been used clinically to alleviate neuropathic pain, while nafamostat mesylate (NM) used clinical on pancreatitis patients through inhibiting synthetic serine protease. Our previous studies showed that NTP and NM were able to repair SCI. However, the underlying mechanism has not been fully explored after treatment with these 2 different drugs.

Methods: The drugs NTP and NM were administered on a contusion SCI Wistar rat model. Cytokine array analysis was performed to describe the changes of 67 proteins after acute SCI. Hierarchical clustering and volcano plot analysis were conducted to clarify protein change profiles. The differently expressed proteins related to biological processes were analyzed by functional protein association networks, Gene Ontology and pathway analysis. Flow cytometric analysis was detected to reflect the activation of immune system after drug intervention, while withdrawal threshold and BBB score were detected to evaluated the mechanical allodynia and functional recovery after SCI.

Results: HGF, $\beta$-NGF, and activin were the 3 most upregulated proteins, while the receptor for RAGE, IL- $1 \alpha$, and TNF- $\alpha$ were the 3 most downregulated proteins after NTP treatment. Adiponectin, decorin and CTACK were the 3 most upregulated proteins, while RAGE, IL- $1 \alpha$, and IL- $1 \beta$ were the 3 most downregulated proteins in the NM group. Number of lymphocytes was decreased while BBB score was increased both in NTP and NM group. But only NTP could improve mechanical pain threshold after SCI.

Conclusions: The PI3K-Akt, Jak-STAT signaling pathway and apoptosis might participate in SCI restoration by NTP, while the MAPK and NOD-like receptor signaling pathway may participated in repairing SCI with NM. We concluded that NTP regulated the microenvironment via a neuroprotective effect and inhibition of inflammation to repair SCI, while NM healed SCI through an anti-inflammatory effect. Both NTP and NM could down-regulate the activation of immune system and improve the functional recovery while only NTP could improve the pathological neuralgia after SCI. Elucidating the molecular mechanisms of these 2 clinical drugs indicates that they their expected to be effective clinical treatment for SCI.

Keywords: Spinal cord injury (SCI); microenvironment; cytokines; neurotropin (NTP); nafamostat mesylate (NM)

Submitted Jan 21, 2021. Accepted for publication Mar 11, 2021.

doi: 10.21037/atm-21-649

View this article at: http://dx.doi.org/10.21037/atm-21-649 


\section{Introduction}

Spinal cord injury (SCI) causes devastating impairment to the central nervous system (CNS) and delivers a heavy physical and social blow to individuals and their families socially. Microenvironment imbalance following SCI hinders neuro-regeneration and functional recovery (1). There are more than 1 million spinal injury and SCI patients in China with a growing rate of 120 thousand per year (2). The USA ranks first in the world with the prevalence of SCI (906 per million) while it has only 250 SCI patients per million in Rhone Alpes, France. Classification of SCI involves discriminating between traumatic and non-traumatic injury. Traumatic SCI is much more common than non-traumatic injury and is usually caused by an external body impact while non-traumatic SCI results from compression by tumor, congenital disease or vascular ischemia. The microenvironment balance is disrupted following contusion SCI, leading to cascading pathological changes including downregulation of beneficial factors while upregulation of harmful factors, which hinders neuro-regeneration and functional recovery (3). Imbalance of the microenvironment consists of molecules, cells and tissues levels at different times and locations. The molecular level including neurotrophic factors, inflammation factors which contributes in rebalancing the microenvironment. As to the cellular level, it includes the activation of astrocytes, microglia and macrophages which infiltrated to the injury site. While the bleeding ischemia, glial scarring, demyelination and remyelination are the main changes at the tissue level. Changing the expression of cytokines and restoring balance to the microenvironment could promote functional recovery after SCI (4-6).

Neurotropin (NTP), a non-protein biological mixture purified from inflamed rabbit skin injected with vaccinia virus, consists of more than 300 ingredients and many of them shown the neuroprotective effects, for instance, GABA, carnosine and adenosine (unpublished data), and it has been used as an analgesic and anti-allergic agent in clinical work (7). Moreover, NTP could be effective against edema and inhibit hippocampal neuronal damage depending on its neuroprotective effects (8). Research has shown that NTP could inhibit neuroinflammation and reverse the memory loss in Alzheimer's disease (9). Nafamostat mesylate (NM), an inhibitor of synthetic serine protease, which plays an important role in inflammation as well as CNS degenerative disorders, has been clinically used to treat acute pancreatitis, disseminated intravascular coagulopathy, and continuous renal replacement therapy. Research showed that NM exerted neuroprotective effect by preventing neurological damage in the animal model of shock. Moreover, it could repair brain injury through curbing activation and infiltration of inflammatory cells and reducing the brain edema volume. Our previous study found that NTP could repair the injured spinal cord to some extent by restraining inflammatory response and apoptosis (10), while NM could attenuate inflammation and improve locomotion recovery after SCI (11).

Previous studies have focused on the effectiveness of pharmaceuticals in repairing SCI, however, the concrete moderating effect of NTP or NM in relation to microenvironment rebalancing after acute SCI has yet to be investigated. Thus, we performed system analysis and comparison of the expression of various cytokines through protein array technology to explain the different effects of NTP and NM on SCI microenvironment rebalancing. Our study aimed to provide new insight into underlying mechanism, novel therapeutic methods, and accelerate medical treatment in SCI.

We present the following article in accordance with the ARRIVE reporting checklist (available at http://dx.doi. org/10.21037atm-21-649).

\section{Methods}

\section{Animals}

The 10-week-old female Wistar rats with the weight of $250 \pm 25 \mathrm{~g}$ were provided by Laboratory Animal Center of the Academy of Military Medical Sciences and housed under continuous humidity conditions in 12 hours day/ night cycles. The experimental processes have been approved by the Ethics Committee of Tianjin Institute of Radiation Medicine (IRM-DWLL-2019039) and according to the National Institutes of Health in the Guide for the Care and Use of Laboratory Animals (NIH Publications No. 85-23, revised 1996).

\section{Experimental groups}

Rats were randomly divided into four groups: Sham group, laminectomy and $0.9 \% \mathrm{NaCl}$; Injury group, SCI and $0.9 \%$ $\mathrm{NaCl}$; NTP group, SCI and $50 \mathrm{NU} / \mathrm{kg} \mathrm{NTP}$; and NM group, SCI and $10 \mathrm{mg} / \mathrm{kg}$ NM. Every group has 30 rats. Intervention doses of these two drugs were determined basing on our previous researches $(10,11)$. Administration of 
NTP and NM was by intraperitoneal injection immediately post-surgery. While Sham group and Injury group treated with same dose of $0.9 \% \mathrm{NaCl}$.

\section{$S C I$}

The spinal cord contusion model was chosen to simulate human spinal cord injury with a New York University Impactor device (NYU, New York, USA) (12). Briefly, rats were anesthetized with pentobarbital and the spinal cord was exposed after T10 laminectomy. The spinal cord was hit with a $10 \mathrm{~g} \times 25 \mathrm{~mm}$ free dropped node. When the spinal cord was injured by the node, the tail was twisted and the hindlimbs were shaken immediately. The incision was then sutured, and the rats were kept on a warm pad until they regained consciousness. While Sham group only received laminectomy.

\section{Protein array detection}

The proteins of spinal cord samples were extracted and detected according to the Rat Cytokine Array 67 (Raybiotech, Norcross, GA, USA) manufacturer instructions. Briefly, the proteins in spinal cord samples were extracted with a cell lysis buffer and protease inhibitor cocktail (Raybiotech, Norcross, GA, USA). After determining the protein concentration of samples with a bicinchoninic acid (BCA) protein assay kit (Raybiotech, Norcross, GA, USA), the samples were incubated with protein array glass slides. Each cell of the glass slides was filled with $100 \mu \mathrm{L}$ sample $(500 \mu \mathrm{g} / \mathrm{mL})$ and incubated at $4{ }^{\circ} \mathrm{C}$ overnight. Then, the slides were washed with Thermo Scientific Wellwash Versa (Thermo Scientific, Waltham, MA, USA) and incubated with biotinylated antibody cocktail and Cy3 equivalent dye-streptavidin (Georgia, USA, RayBiotech, QA-CY3E). The signals could then be visualized through a laser scanner. Serial dilutions of a predetermined calibration standard mix were used to generate a standard curve for each cytokine. The cytokine concentrations in samples were calculated according to the standard curve.

\section{Identification of differentially expressed proteins (DEPs)}

The raw dataset was preprocessed via using Affy packages in $\mathrm{R}$. Then the data transfer to the gene expression matrix of the probe. DEPs were screened by $\mathrm{R}$ package limma. The DEPs with an adjust $P$ value $<0.05$ and $\mid \log 2$ fold-change $(\log 2 \mathrm{FC}) \mathrm{I} \geq 1$. Then screened DEPs were used to create a volcano-plot analysis with a standard $\log 2 \mathrm{FC}$ to determine the expression of DEPs in each sample.

\section{PPI (Protein-Protein -Interaction) network and Function Enrichment analysis PPI was used to focus on proteins in biochemical processes}

to understand the bioprocess, cellular organization, and functions by STRING 11.0. Both GO functional and KEGG pathway enrichment analysis for DEPs were used the $\mathrm{R}$ package. The $\mathrm{P}$ value $<0.05$ was considered statistically significant.

\section{Western blot}

The proteins in spinal cord samples were extracted with cell lysis buffer and a protease inhibitor. Equal amounts of total tissue lysate were resolved by SDS-PAFE, and transferred them to PVDF membranes. Then, these membranes were immunoblotted overnight with the primary antibodies. After that, the membranes washed three times with Tris-buffered saloine-Tween (TBST), and corresponding secondary antibodies was added for 1.5 hours. Finally, the images were visualized by using the electrochemiluminescence (ECL) method.

\section{Flow cytometric analysis}

The injured spinal cord epicenters were isolated and placed in Hank's Balanced Salt Solution (Biyun Biotechnology, Shanghai, China). Then the tissue samples were adjusted the cell concentration to $2 \times 10^{6} / \mathrm{mL}$ after filtering through a $70 \mu \mathrm{m}$ filter. The paraformaldehyde $(4 \%, \mathrm{w} / \mathrm{v})$ in PBS was used to fix cells and permeabilized with $0.1 \%$ saponin at room temperature, and finally added CD4, CD19 antibodies to the samples in dark and then assessed with a flow cytometer (BD Biosciences, san Jose, CA, USA).

\section{Enzyme-linked immunosorbent assay}

Spinal cord tissue was dissected $1 \mathrm{~cm}$ of injured site at 3 days following spinal cord contusion $(\mathrm{n}=6)$, placed in precooled PBS buffer, and homogenized. The supernatant was collected by centrifugation at 3,000 r/min for $20 \mathrm{~min}$. Finally, the total protein of each sample was quantitated according to the instructions of the ELISA kits (Biyun Biotechnology, Shanghai, China). 


\section{Locomotion recovery assessment}

Basso Beattie Bresnahan (BBB) locomotion scale was assessed to evaluate the recovery of motor function depending on a scale $0-21$ points with a total of 22 grades. Three tests were taken to obtain an average value for each rat. The testing was performed weekly until 4 weeks after SCI.

\section{Evaluation of mechanical allodynia}

All rats were assessed mechanical allodynia by Von Frey device after habituating $30 \mathrm{~min}$. The lowest bending force at which the rat withdrew its paw was determined as the threshold of nociceptive. The threshold was recorded as an average of both hind paws.

\section{Statistical analysis}

Experimental data were analyzed using SPSS 20.0 software and expressed as the mean \pm standard error of the mean. The statistical differences in protein expression between two groups were evaluated by Student's unpaired $t$-test. For more than two group, statistical significance was determined with one-way analysis of variance (ANOVA) test followed by Bonferroni correction. A value of $\mathrm{P}<0.05$ was considered statistically significant.

\section{Results}

\section{Hierarchical clustering analysis of protein profiles after SCI treated by NTP and NM}

Hierarchical clustering was conducted to clarify the 67 proteins changed profiles after SCI, and then NTP and NM treatment. Each group has 6 rats and has no adverse events. As shown in Figure $1 A, B, C$, there were different changes after SCI and treatment by these 2 kinds of drugs, in addition, more protein changes occurred after NTP treatment than after NM treatment and those proteins were focused on increasing form. There were 15 upregulated and 9 downregulated proteins after NTP treatment, while 10 and 9 in the NM treatment group, respectively. We divided these 67 proteins into 3 clusters: High expression group $(\geq 500 \mathrm{pg} / \mathrm{mL}$ ), Middle expression group $(50<$ expression $\leq 500 \mathrm{pg} / \mathrm{mL})$, and Low expression group $(\leq 50 \mathrm{pg} / \mathrm{mL})$ (Table 1). Among the 67 proteins, Low expression proteins predominated $(n=31)$, High expression proteins ranked second $(n=20)$, and Middle expression proteins number were the least common $(\mathrm{n}=16)$. The Low expression cluster had more changed proteins than the other 2 clusters after NTP or NM treatment (Figure 1D).

\section{Protein expression patterns after SCI}

We divided these changed proteins into 4 expression patterns with the changes after SCI and then treatment by NTP: Ns-Increase (NI pattern, 7 proteins, Figure 2), Decrease-Increase (DI pattern, 7 proteins, Figure 3), Increase-Increase (II pattern, 2 proteins, Figure 4), and Increase-Decrease (ID pattern, 9 proteins, Figure 5). Among the 4 patterns, NI, DI and II all belonged to the Increase group, which indicated increasing was the main trend of most proteins after NTP treatment. There were 3 different patterns in the NM treatment: Ns-Increase (NI pattern, 5 proteins, Figure 6), Decrease-Increase (DI pattern, 5 proteins, Figure 7), and Increase-Decrease (ID pattern, 9 proteins, Figure 8). The changed proteins had a different trend in upward and downward regulation after NM treatment compared with the NTP treatment group.

\section{DEPs after SCI treated with NTP and NM}

Volcano-plot analysis was conducted to better demonstrate the DEPs after NTP and NM treatment (Figure 9). The proteins were taken into consideration when the $\mathrm{FC}$ was over 1 or less than -1 . After NTP treatment, there were 15 upregulated and 7 downregulated proteins. Hepatocyte growth factor (HGF), beta-nerve growth factor ( $\beta$-NGF) and Activin A were the 3 most upregulated proteins, while the receptor for advanced glycation end products (RAGE), interleukin 1-alpha (IL-1 $\alpha$ ), and tumor necrosis factor-alpha (TNF- $\alpha$ ) were the 3 most downregulated proteins. After NM treatment, there were 6 upregulated and 4 downregulated proteins. Adiponectin, Decorin, and cutaneous T-cell attracting chemokine (CTACK) were the 3 most upregulated, while RAGE, IL- $1 \alpha$, and IL- $1 \beta$ were the 3 most downregulated proteins.

\section{Key proteins analysis in acute phase of SCI treated by NTP and NM}

To find out the key proteins that might play a pivotal role after NTP and NM treatment, the DEPs were shown in a Venn plot (Figure 10A). As shown in Figure 10B, Decorin, adiponectin, CTACK, HGF, $\beta$-NGF, and B7-2 were all increased in the NTP and NM treatment groups, 
A

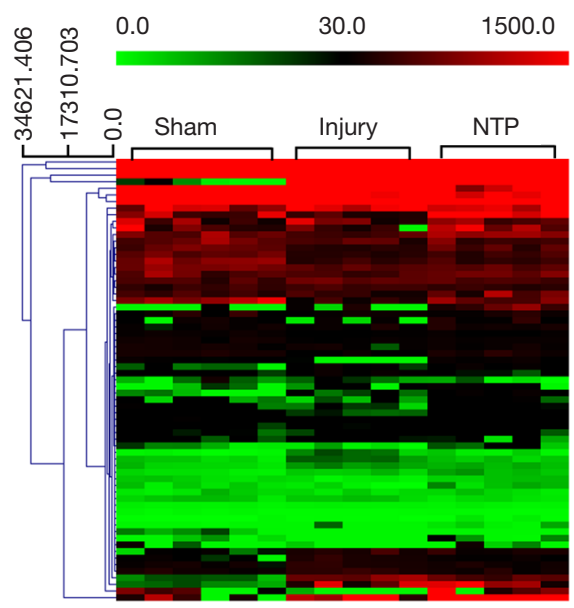

C

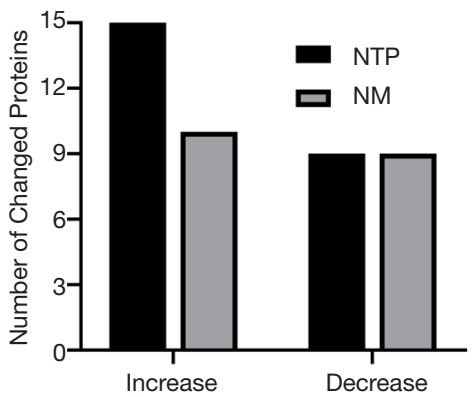

B

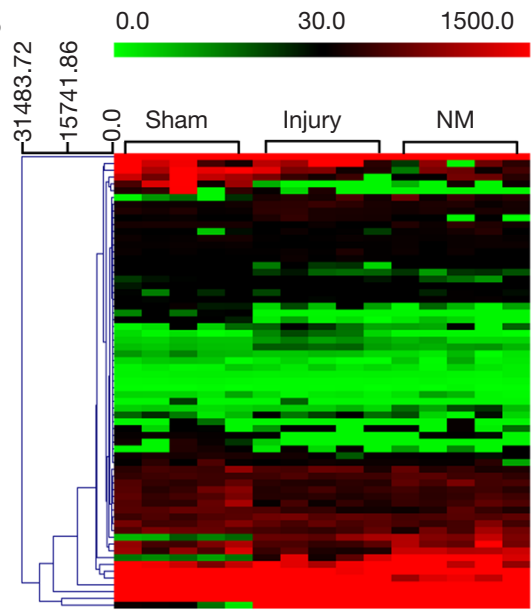

D

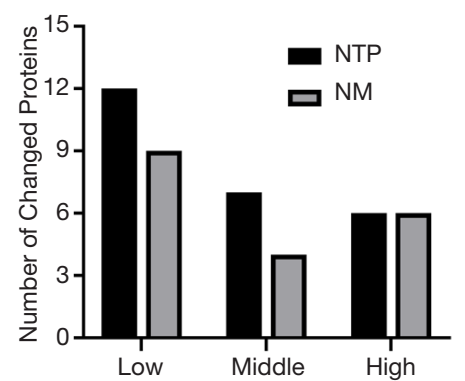

Figure 1 Protein profiles after SCI and treated by NTP and NM. (A,B) Heat-map showing upregulated proteins (red) and downregulated proteins (green) between Sham, Injury, NTP, and NM groups. (C) The number of changed proteins in increase and decrease trends of NTP and NM group. (D) The number of changed proteins in high, middle, and low trend of NTP and NM group. SCI, spinal cord injury; NTP, neurotropin; NM, nafamostat mesylate.

Table 1 The 3 clusters of the 67 proteins

\begin{tabular}{ll}
\hline Cluster & Gene symbols \\
\hline High & Decorin, Notch-1, Neuropilin-2, Erythropoietin, Activin A, ICAM-1, Prolactin R, Notch-2, Nope, Adiponectin, Neuropilin-1, \\
& IL-1 ra, 4-1BB, CNTF, gp130, GFR alpha-1, IL-1 R6, CTACK, TCK-1, Galectin-1 \\
Middle & IL-1 $\alpha, I L-7$, CD48, Prolactin, FGF-BP, Gas 1, JAM-A, IL-6, Fractalkine, EphA5, IL-10, HGF, IL-22, PDGF-AA, Galectin-3, B7-1 \\
& LEGF, IL-4, RAGE, IFNg, TIM-1, RANTES, $\beta-N G F, I L-13, I L-3, I L-1 \beta$, LIX, IL-17F, TIMP-2, L-Selectin, CINC-2, MCP-1, MIP- \\
& 1a, FIt-3L, IL-2 Ra, SCF, TWEAK R, CINC-3, TREM-1, IL-2, Extoxin, TIMP-1, CINC-1, p-Cadherin, B7-2, TNF-a, GM-CSF \\
\hline
\end{tabular}

and the expression of IL- $1 \alpha$, fractalkine, RAGE, IL-1 $\beta$, LPS-induced CXC chemokine (LIX), TNF-a were all decreased in these 2 experimental groups. The only protein that was upregulated after NTP treatment while being downregulated in NM treatment group was TIMP-1.

\section{Construction of a PPI network and Function Enrichment analysis in NTP treatment}

To better clarify the biological processes of DEPs at different timepoints after SCI, PPI, Kyoto Encyclopedia of Genes and Genomes (KEGG), and GO enrichment 

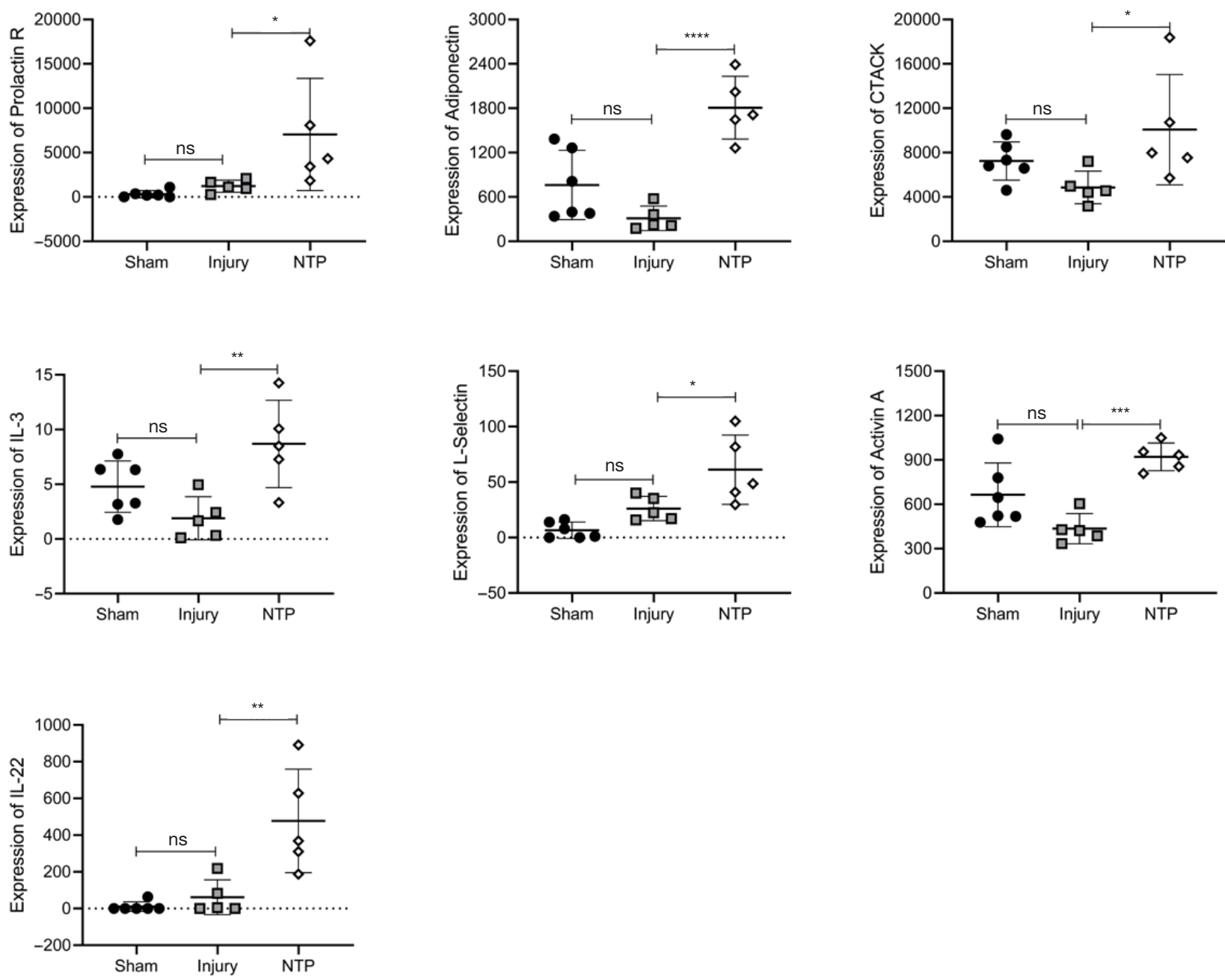

Figure 2 The proteins with a ns-increase pattern in NTP group. Protein expression analysis showed 7 proteins presented the ns-increase expression trend in NTP group. NTP, neurotropin. ${ }^{*} \mathrm{P}<0.05,{ }^{* *} \mathrm{P}<0.01,{ }^{* * *} \mathrm{P}<0.001,{ }^{* * * *} \mathrm{P}<0.0001$.

analyses were established. The interactions of DEPs were analyzed with STRING online database to determine PPI among nodes underlying SCI (Figure 11A). Then the hub genes which including MCP-1, IL-13 and HGF in PPIs were verified by western blot and these proteins showed the same expressing trends with the results of protein chip (Figure 11B,C). Response to stimulus, Positive regulation of cellular process, Regulation of signaling receptor activity, Regulation of cell population proliferation, Regulation of signal transduction, Regulation of multicellular organismal development, Positive regulation of cell population proliferation, Regulation of signaling receptor activity, and Positive regulation of protein phosphorylation were the 10 most common GO biological processes. Protein binding, Molecular function regulation, Regulation of signal transduction, Signal receptor binding, and Cytokine receptor binding were the 5 most enriched GO molecular functions. Cell, Cell part, and Extracellular region were the top 3 enriched GO cellular components (Figure 11D,E,F). As shown in Figure 11G, Cytokine-Cytokine receptor interaction, PI3K-Akt signaling pathway, Jak-STAT signaling pathway, TNF signaling pathway, IL-17 signaling pathway, and Apoptosis were the top 6 pathways.

\section{Construction of a protein-protein-interaction (PPI) network} and Function Enrichment analysis in NM treatment

The PPIs after NM treatment are shown in Figure $12 \mathrm{~A}$. Then the hub genes which including Fractalkine, timp1 and tck-1 in PPIs were verified by western blot and 

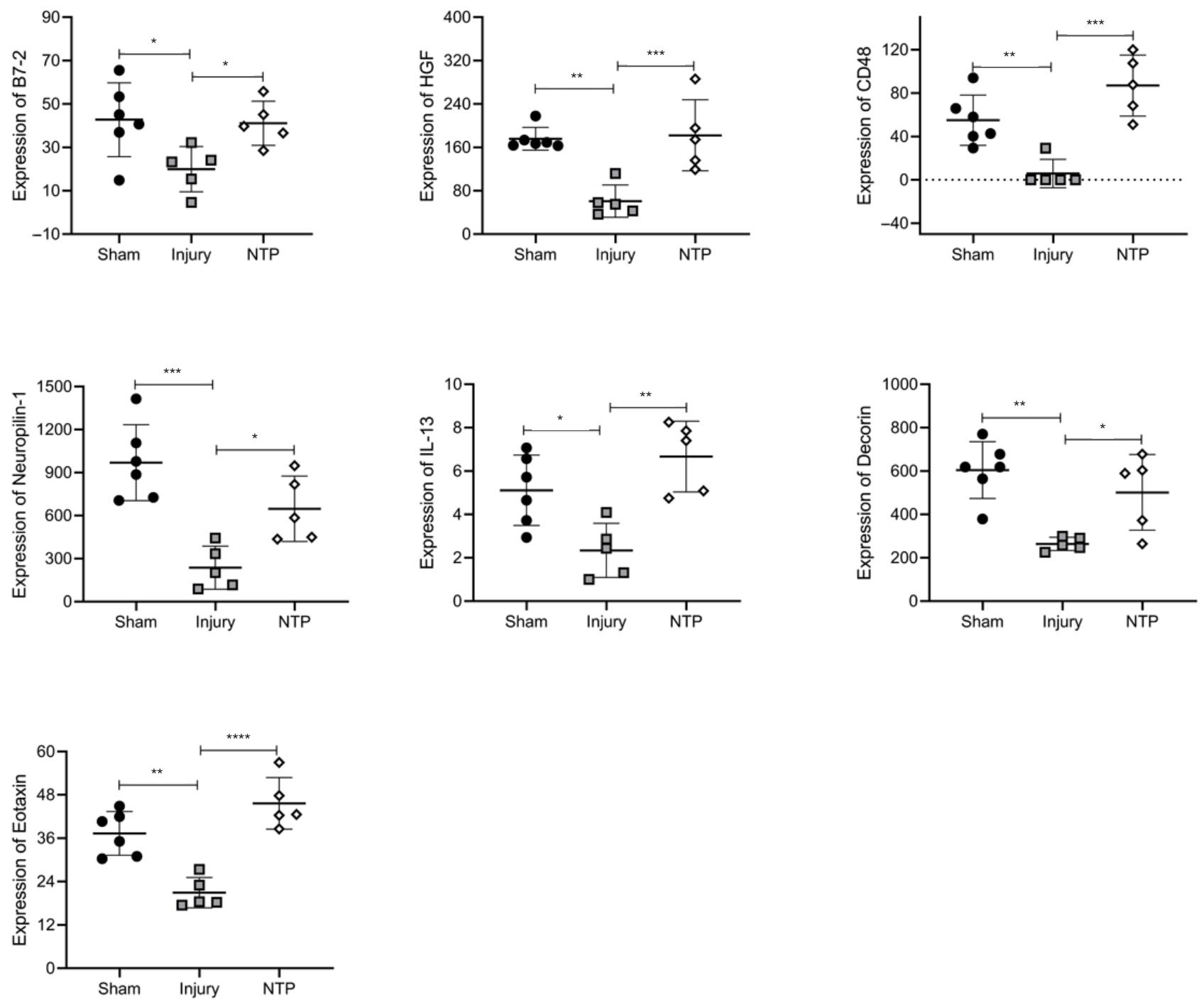

Figure 3 The proteins with decrease-increase pattern in NTP group. Protein expression analysis showed 7 proteins presented the decreaseincrease expression trend in NTP group. NTP, neurotropin. ${ }^{*} \mathrm{P}<0.05,{ }^{* *} \mathrm{P}<0.01,{ }^{* * *} \mathrm{P}<0.001,{ }^{* * * *} \mathrm{P}<0.0001$.

these proteins showed the same expressing trends with the results of protein chip (Figure 12B,C). Different from NTP treatment, Response to chemical, Response to organic substance, Regulation of cell communication, Regulation of signaling, Regulation of response to stimulus, Positive regulation of cellular process, Regulation of localization, Cell surface receptor signaling pathway, Regulation of signaling receptor activity, and Cytokine-mediated signaling pathway were the 10 most common GO biological processes. Protein binding, molecular function regulation, signaling receptor binding, receptor ligand activity, and cytokine receptor binding were the 5 most enriched GO molecular functions. Extracellular region, Extracellular region part, and Extracellular space were the top 3 enriched GO cellular components (Figure 12D,E,F). As shown in Figure 12G, Chemokine signaling pathway, IL-17 signaling pathway, TNF signaling pathway, MAPK signaling pathway, NOD-like receptor signaling pathway, and Inflammatory mediator regulation of transient receptor potential (TRP) channels were the top 6 pathways. 

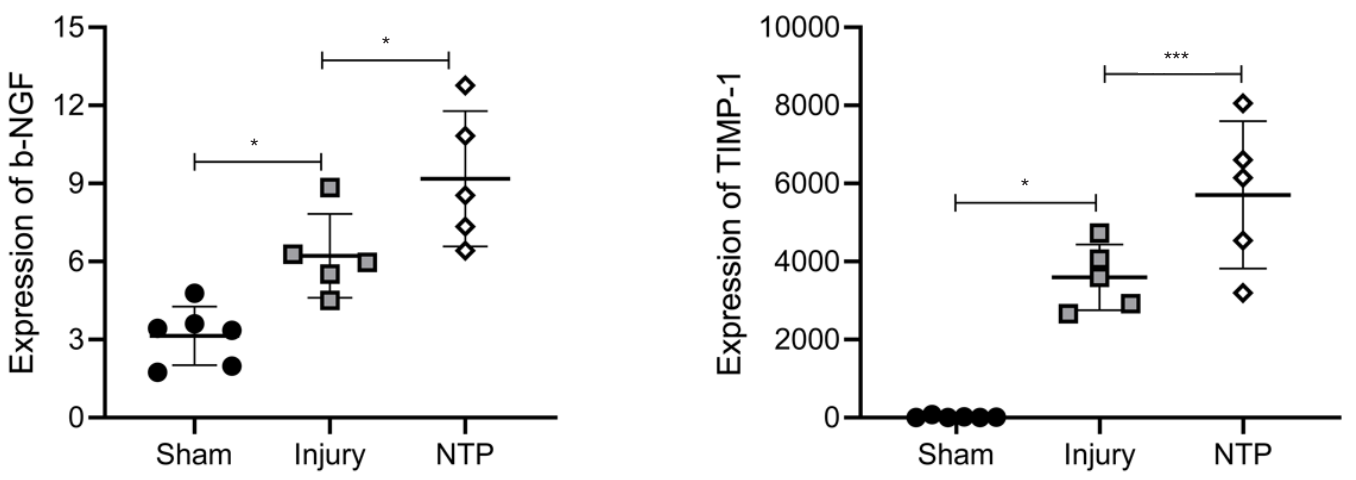

Figure 4 The proteins with an increase-increase pattern in NTP group. Protein expression analysis showed 2 proteins presented the increase-increase expression trend in NTP group. NTP, neurotropin. ${ }^{*} \mathrm{P}<0.05,{ }^{* * *} \mathrm{P}<0.001$.

\section{Infiltration of $\mathrm{CD}^{+} \mathrm{T}$ cells and $\mathrm{CD} 19^{+} \mathrm{B}$ cells into the spinal cord was decreased after NTP or NM treatment}

SCI results in disruption of blood spinal cord barrier, number of lymphocytes in the center of SCI was detected by flow cytometric analysis which could reflect the activation of immune system after drug intervention. As is shown in Figure 13, the number of $\mathrm{CD}^{+} \mathrm{T}$ cells and $\mathrm{CD} 19^{+} \mathrm{B}$ cells were significantly reduced by NTP or NM treatment. Thus, these results demonstrate that there was less lymphocyte infiltration after NTP or NM treatment.

\section{Expressions of key factors after NTP or NM treatment}

The ELISA was performed to verify the key factors at 3 days post-surgery. As shown in Figure 14, TNF- $\alpha$ and IL-1 $\beta$ were reduced while HGF and NGF were increased after NTP treatment. In contrast, only decreased expression of TNF- $\alpha$ and IL- $1 \beta$ could be observed in the NM treatment group. The results showed that NTP may influence the neurotrophic factors while NM could inhibit neuroinflammatory factors to modulate recovery from SCI.

\section{Functional test and mechanical allodynia after SCI by NTP or NM}

To detect the different efficacy of these 2 drugs in treating SCI, BBB score and withdrawal threshold were applicated from Day1 until 4 weeks after SCI. BBB score showed a significant difference between Injury group and NTP group or Injury group and NM group after 2 weeks post-injury, which indicated that both them could promote the recovery of motor function (Figure 15A). While only NTP treatment could improve mechanical pain threshold after SCI (Figure 15B).

\section{Discussion}

The internal regeneration ability of neurons (13) and the external inhibitory microenvironment were the two major factors leading to the failure of axonal regeneration in the CNS and the microenvironment imbalance which has tissue, cellular and molecular levels could be the biggest obstacle to recovery of SCI. No matter what level of microenvironment imbalance could aggravate nerve damage to varying degrees. Glia scars spatially hinder axon regeneration (14) while infiltration of large numbers of macrophages and microglia aggravate inflammation of the injury site (15), for example. Balance of the microenvironment is destroyed in the wake of SCI, resulting in a series of pathophysiological changes, including the downregulation of beneficial factors and upregulation of harmful factors. Various cellular and hormonal inflammatory factors are related to the imbalanced microenvironment following SCI (16). It is known that endogenous microglia, T cells, astrocytes, and macrophages are involved in the main inflammatory response (17). Activation of the inflammatory mechanism of cells and hormones directly or indirectly affects cell necrosis, apoptosis, free radical production, and increased permeability of the blood-brain barrier $(4,18,19)$. Cytokines secreted by immune cells, astrocytes, and microglia express within minutes following SCI (20). Cytokines can be classified into pro-inflammatory or antiinflammatory proteins involved in neuroinflammation, neuropathic pain and neurodegeneration. Neurons located in spinal cord secrete cytokines within 30 minutes after SCI, while microglia start express them after 5 hours, however the expression activity of both of them become weaker by the second day. In addition, astrocytes and epidermal cells could express TNF $\alpha$ and IL-6 either. A variety of 

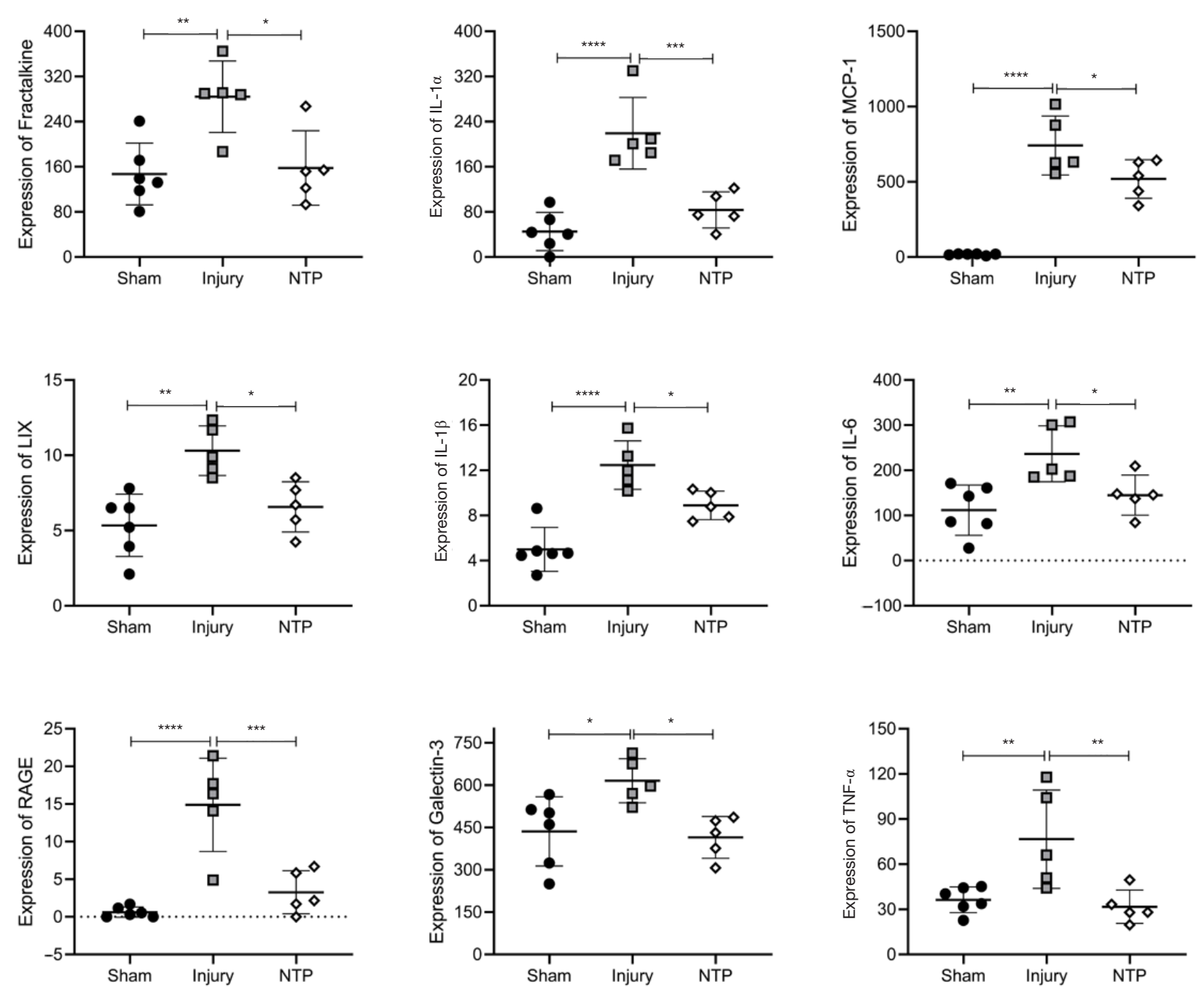

Figure 5 The proteins with -increase-decrease pattern in NTP group. Protein expression analysis showed 7 proteins presented the decreaseincrease expression trend in NTP group. NTP, neurotropin. ${ }^{*} \mathrm{P}<0.05,{ }^{* *} \mathrm{P}<0.01,{ }^{* * *} \mathrm{P}<0.001,{ }^{* * *} \mathrm{P}<0.0001$.

cytokines including TNF- $\alpha$, IL-1, IL-6, GM-CSF, LIF, etc. participate in the imbalance and rebalance of the SCI microenvironment. It is of great significance to clarify the cytokine expression profile after SCI. Unlike PCR, ELISA, and western blotting, which can only detect one marker one time, cytokine array $(21,22)$ is a sensitive, specific, small sample, and multi protein detection method (up to 500 markers), which makes it an optimal choice to describe protein expression profiles after SCI.

The rebalance of the microenvironment is crucial to the repair process of SCI (23). Inhibiting the formation of glial scar and rebalance the microenvironment at the tissue level could remove the spatial obstacle to axon regeneration (24).
As to the cellular level, the imbalance of the doubleedged sword function of macrophages can be regulated by inhibiting activation and promoting the protective effects of repairing SCI (25). Reducing the release of inflammatory factors and increasing the expression of neurotrophic factors, which can rebalance the molecular level microenvironment and promote the recovery of sensory and motor function (26). The drug NTP is a kind of multicomponent biological agent while NM is a chemical agent, which determines their own unique functions on microenvironment in SCI treatment. A non-protein extract isolated from inflamed rabbit skin inoculated with vaccinia virus, NTP is used to treat intractable neuropathic pain in clinical work $(27,28)$. 

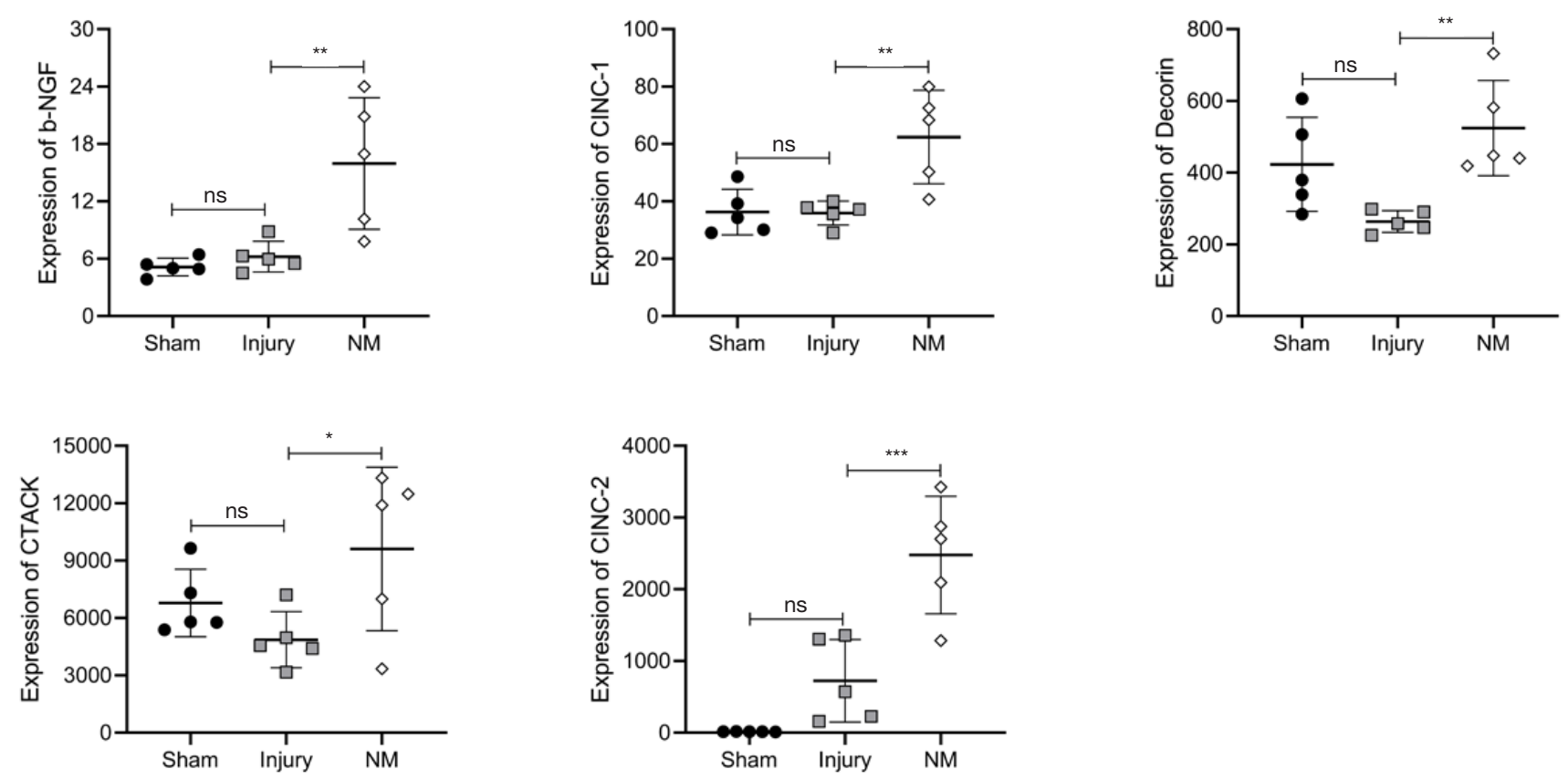

Figure 6 The proteins with a ns-increase pattern in NM group. Protein expression analysis showed 5 proteins presented the ns-increase expression trend in $\mathrm{NM}$ group. $\mathrm{NM}$, nafamostat mesylate. ${ }^{*} \mathrm{P}<0.05,{ }^{* *} \mathrm{P}<0.01,{ }^{* * *} \mathrm{P}<0.001$.

Analysis of its components showed that NTP was composed of more than 300 small molecular compounds and some of them have been showed neurotrophic effect, such as GABA, carnosine and adenosine. Previous research has reported that NTP could reduce neuroinflammation and improve cognitive dysfunction through brain derived neurotrophic factor/nuclear factor kappa light chain enhance of $B$ cells $(\mathrm{BDNF} / \mathrm{NF}-\kappa \mathrm{B})$ pathway $(9,29,30)$. Moreover, NTP had a protective effect on ischemic stroke (31), promoted demyelination of demyelinating disease (32), and reduced muscular mechanical hyperalgesia (33). Treatment with NTP significantly increased the expression of BDNF and inhibition of BDNF receptors could abolish this effect (9). These studies showed that NTP could inhibit neuroinflammation and play a neuroprotective role in neurodegenerative diseases which respond to its rich ingredients. Our previous study found that NTP could promote the functional repair of SCI. Treatment with NTP could protect spinal cord tissue, reduce glial proliferation and apoptosis, up regulate neurotrophic factor, and down regulate pro-inflammatory cytokines after SCI. NM, an inhibitor of synthetic serine protease, has been used in treating acute pancreatitis, continuous renal replacement therapy and disseminated intravascular coagulation (34-36). Research showed that thrombin could to upregulate proinflammatory cytokines from activating astrocytes and microglia (37), while NM was effective in repairing cerebral ischemia through inhibiting thrombin activation (38). Our previous studies have shown that NM could attenuate aggregation of microglia/macrophages, expressions of thrombin, and pro-inflammatory cytokines after SCI. Application of NM promoted the functional recovery of rats with SCI by inhibiting neuroinflammation and apoptosis. However, the molecular mechanisms of NTP and NM are not completely clear.

The present study demonstrated that NTP treatment improved the expressions of HGF, $\beta$-NGF, and activin A, which belonged to neuroprotective factors. Among them, HGF is one of the neurotrophic growth factors and has been listed as a candidate medicine for SCI treatment. The significant effect of HGF on nerve regeneration is related to its anti-inflammatory and anti-fibrosis properties $(39,40)$. In addition, HGF has a positive effect on the differentiation of transplanted stem cells into neurons (41). Mature NGF has a neuroprotective effect, which can affect the neural response to injury on cell types displaying NGF receptors, such as nociceptive sensory neurons, $\alpha$ motor neurons, and Schwann cells in the CNS $(42,43)$. Preclinical studies have shown that the introduction of NGF-specific antagonists in mice has neuroprotective 

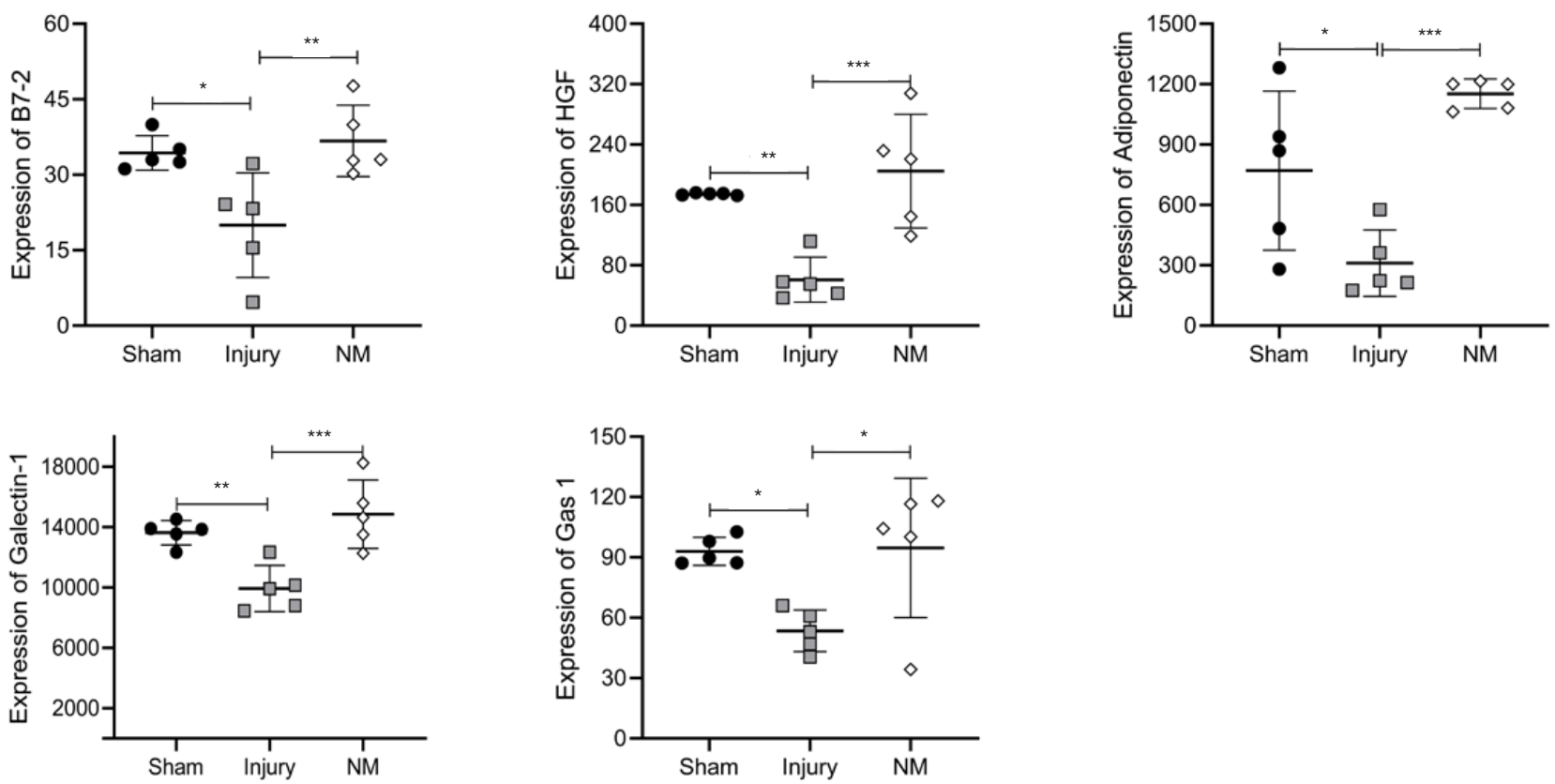

Figure 7 The proteins with decrease-increase pattern in NM group. Protein expression analysis showed 5 proteins presented the decreaseincrease expression trend in NM group. $\mathrm{NM}$, nafamostat mesylate. ${ }^{*} \mathrm{P}<0.05,{ }^{* *} \mathrm{P}<0.01,{ }^{* * *} \mathrm{P}<0.001$.

effects and NGF antagonists also showed positive results after SCI or amyotrophic lateral sclerosis (44). A previous study investigated the effect of activin $\mathrm{A}$, a member of transforming growth factor B ultrasonic family, on healing fibular fracture (45). Moreover, activin A has a neurotrophic function in repairing brain injury $(46,47)$. Compared with the NTP group, adiponectin, Decorin, and CTACK levels were up-regulated after NM treatment. Adiponectin, induced by homologous receptor, could inhibit glucose production in liver, enhance fatty acid oxidation in skeletal muscle, and promote beneficial metabolism of whole-body energy homeostasis. In addition to its role in metabolism, adiponectin could reduce inflammation through receptor dependent mechanisms (48). Decorin plays a discrete role in the signal transduction pathway of fetal membrane in inflammation, leading to changes in the expression of matrix metalloproteinase-8 (MMP-8) and collagen $\alpha 1 \mathrm{VI}$, which are the roles of the extracellular matrix of fetal membrane in the pathophysiology of preterm premature rupture of fetal membranes (49). The chemokine CTACK may be involved in the basic transport of $\mathrm{T}$ cells during normal immune monitoring. However, CTACK can be enhanced by pro-inflammatory cytokines TNF- $\alpha$ and IL- $1 \beta$, which together with the significant up-regulation of vascular
E-selectin, may recruit memory $\mathrm{T}$ cells into the skin during the process of cutaneous inflammation (50). Besides, RAGE, IL- $1 \alpha$, and TNF- $\alpha$, participating in pro-inflammation after SCI, were the 3 most downregulated proteins after NTP treatment, while RAGE, IL- $1 \alpha$, and IL- $1 \beta$ were downregulated proteins in the NM group. Several studies showed that RAGE is a major cellular binding site for HMGB1, which acts as a pattern recognition receptor and participates in improving inflammation, oxidative stress, and neurodegeneration in SCI $(51,52)$. The cytokines IL- $1 \alpha$, IL-1 $\beta$, and TNF- $\alpha$ were typical inflammatory factors aggravating the secondary injury of SCI. Above all, NTP showed its neuroprotective and anti-inflammation effects for recovery from SCI, while NM treated SCI only through inhibiting inflammation.

In this study, we found that the PI3K-Akt and JAKSTAT signaling pathways might participate in the treatment of SCI by NTP. Compared with the NTP group, MAPK and NOD-like receptor signaling pathways might have an important role in the process of NM repairing SCI. As previously demonstrated, the PI3K-Akt pathway, involved in the repair of SCI, plays an important role in the proliferation, development, differentiation, axon regeneration, myelination, apoptosis, and synaptic plasticity 

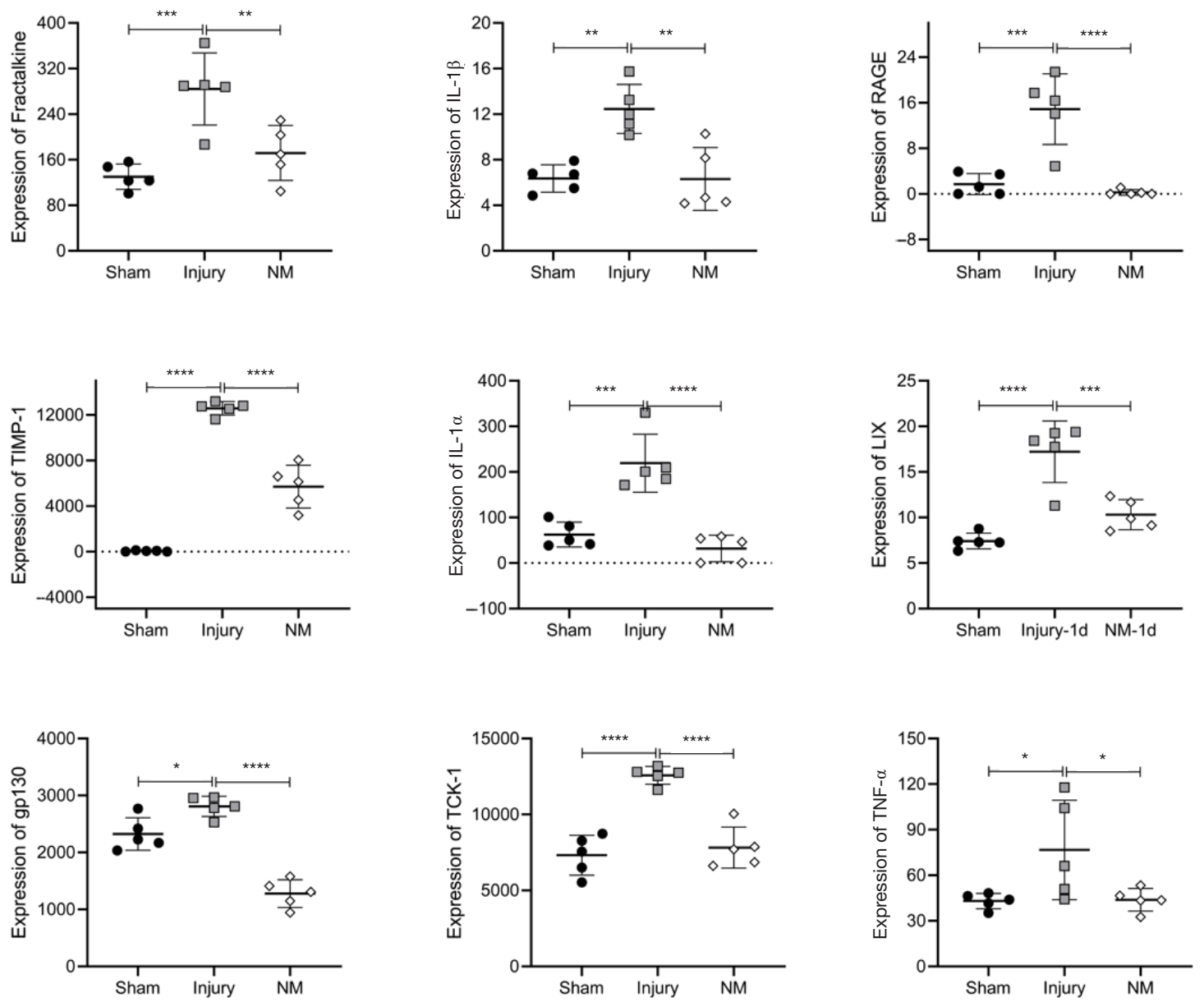

Figure 8 The proteins with -increase-decrease pattern in NM group. Protein expression analysis showed 7 proteins presented the decreaseincrease expression trend in NTP group. NTP, neurotropin. ${ }^{*} \mathrm{P}<0.05,{ }^{* *} \mathrm{P}<0.01,{ }^{* * *} \mathrm{P}<0.001,{ }^{* * * *} \mathrm{P}<0.0001$.
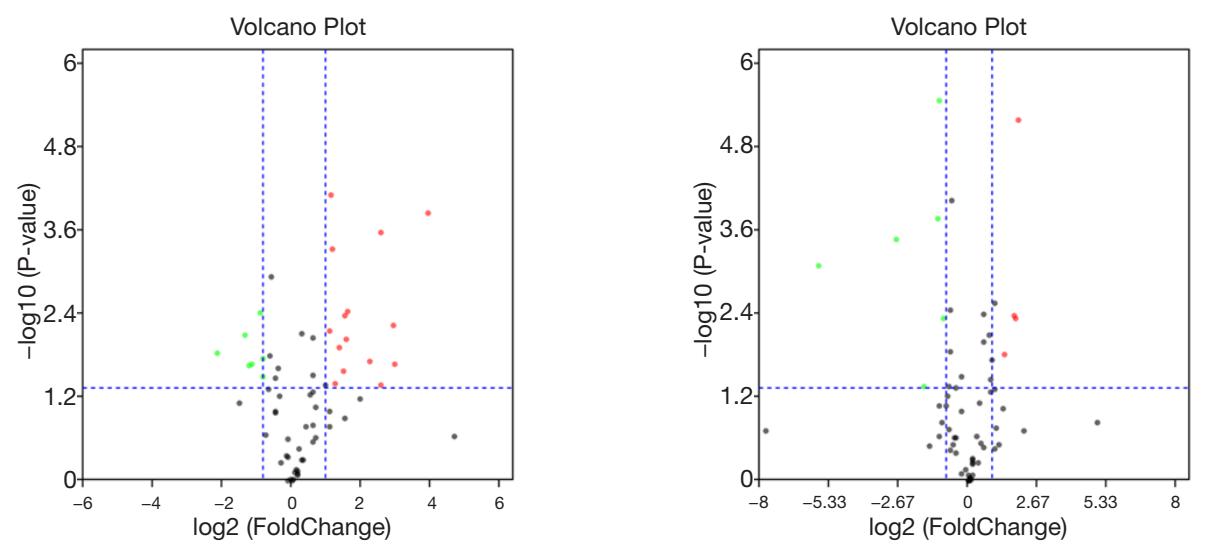

Figure 9 Volcano-plot analysis showed DEPs in NTP (Left) and NM (Right) groups. Volcano-plot analysis showed upregulated genes (red) and downregulated genes (green) between injury and NTP or NM groups. The X-axis was the $\log \mathrm{FC}$, and the 2 dotted lines at X-axis were at $\mathrm{X}=1$ and $\mathrm{X}=-1$, (presented upregulating 2 fold and downregulating 2 fold, respectively). The Y-axis was $-\log 10 \mathrm{P}$ value, and the dotted line at $\mathrm{Y}$-axis was at $\mathrm{Y}=1.30103$ (presented $\mathrm{P}=0.05$ ). The upper right red dots presented DEPs $\mathrm{FC}>1$ and $\mathrm{P}<0.05$, and the upper left green dots presented DEPs FC $<-1$ and $\mathrm{P}<0.05$. DEPs, differentially expressed proteins; NTP, neurotropin; NM, nafamostat mesylate; FC, fold change. 
A

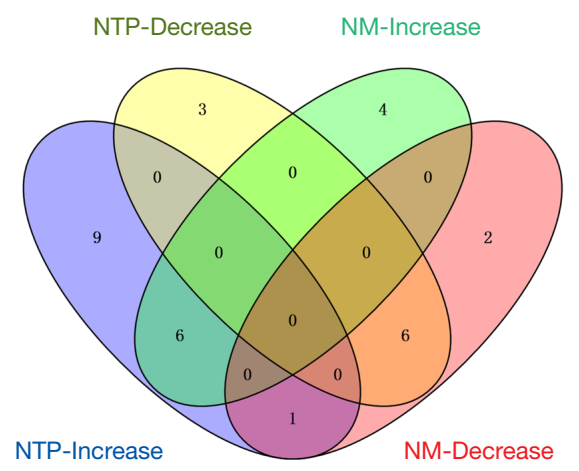

B

\begin{tabular}{|c|c|c|}
\hline Names & Total & Proteins \\
\hline $\begin{array}{c}\text { NTP-Increase } \\
\text { \& NM-Increase }\end{array}$ & 6 & $\begin{array}{l}\text { Decorin Adiponectin } \\
\text { CACK HFF } \\
\beta-N G F \text { B7-2 }\end{array}$ \\
\hline $\begin{array}{c}\text { NTP-Decrease } \\
\text { \& NM-Decrease }\end{array}$ & 6 & $\begin{array}{l}\text { LL-1 } \text { Fractalkine } \\
\text { RAG IL-1 } \\
\text { LIX TF-a }\end{array}$ \\
\hline $\begin{array}{c}\text { NTP-Increase } \\
\text { \& NM-Decrease }\end{array}$ & 1 & TIMP-1 \\
\hline
\end{tabular}

Figure 10 Key protein analysis in NTP and NM groups. (A) Venn diagram showed co-dysregulated proteins in NTP and NM groups. (B) The table showed specific names of co-dysregulated proteins. NTP, neurotropin; NM, nafamostat mesylate.

A

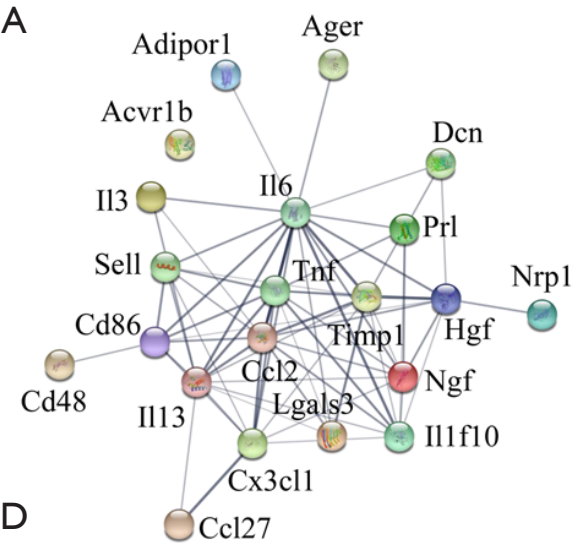

B

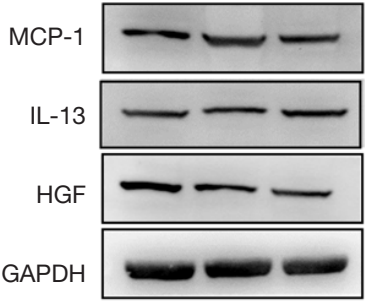

C

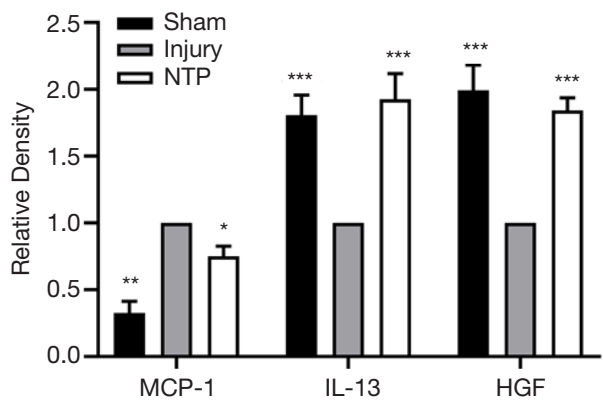

Biological Process (GO)

$\mathrm{E}$

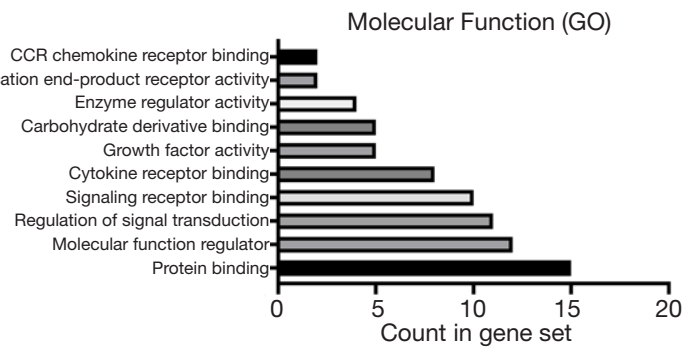

G

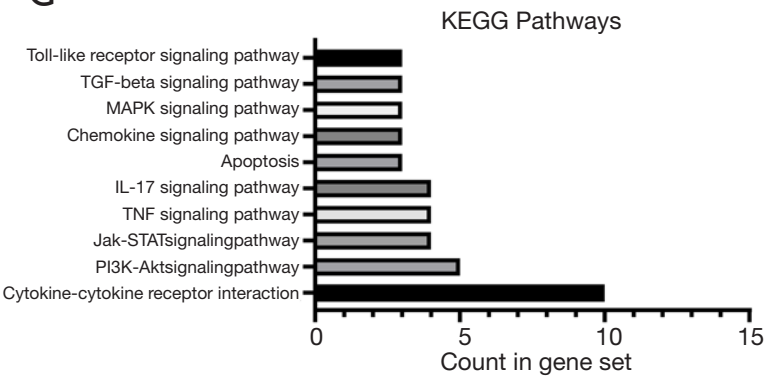

Figure 11 The PPIs, KEGG and GO enrichment analyses of the DEPs in NTP group. PPIs, protein-protein interactions; KEGG, Kyoto Encyclopedia of Genes and Genomes; GO, Gene Ontology; DEPs, differentially expressed proteins; NTP, neurotropin. ${ }^{*} \mathrm{P}<0.05,{ }^{* *} \mathrm{P}<0.01$, ${ }^{* * *} \mathrm{P}<0.001$. 
D

$\mathrm{F}$
A

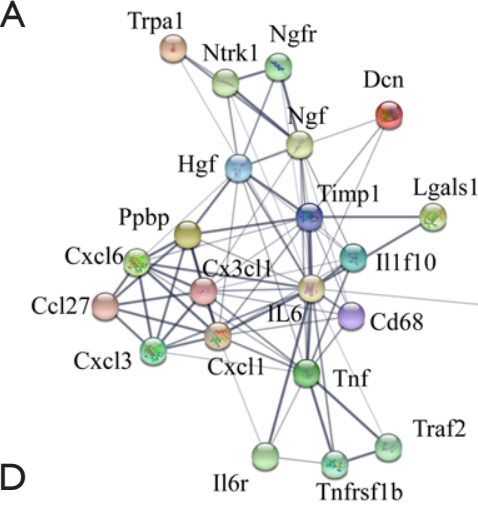

B

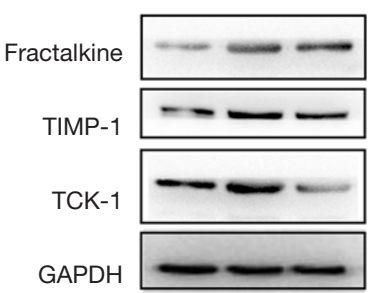

C

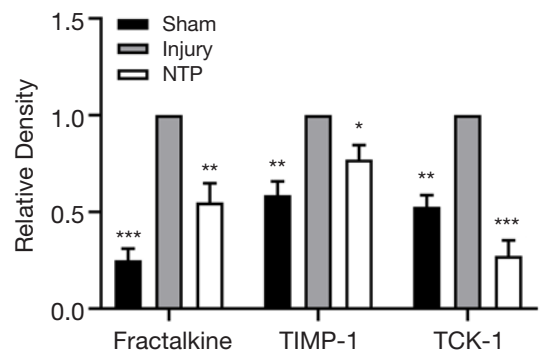

$E$

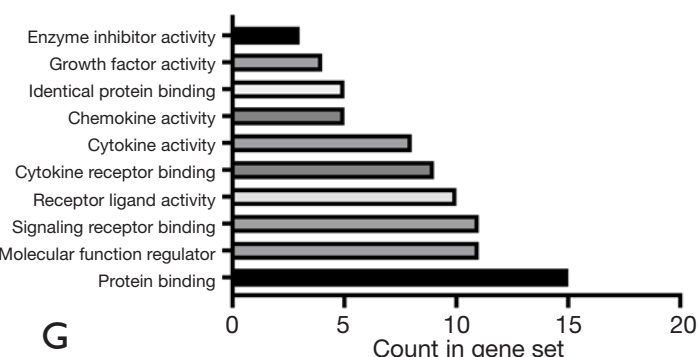

Biological Process (GO)

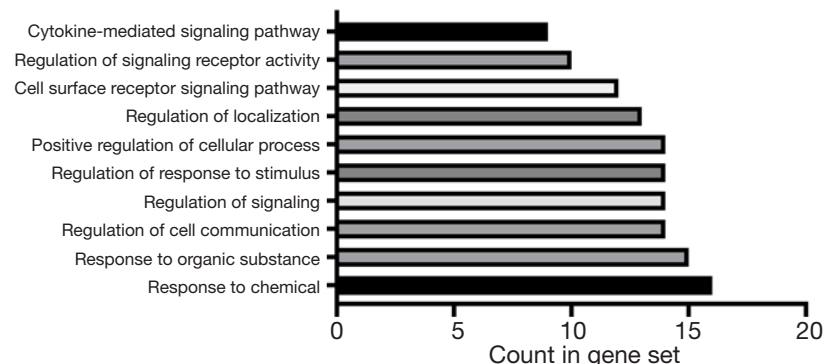

Cellular Component (GO)
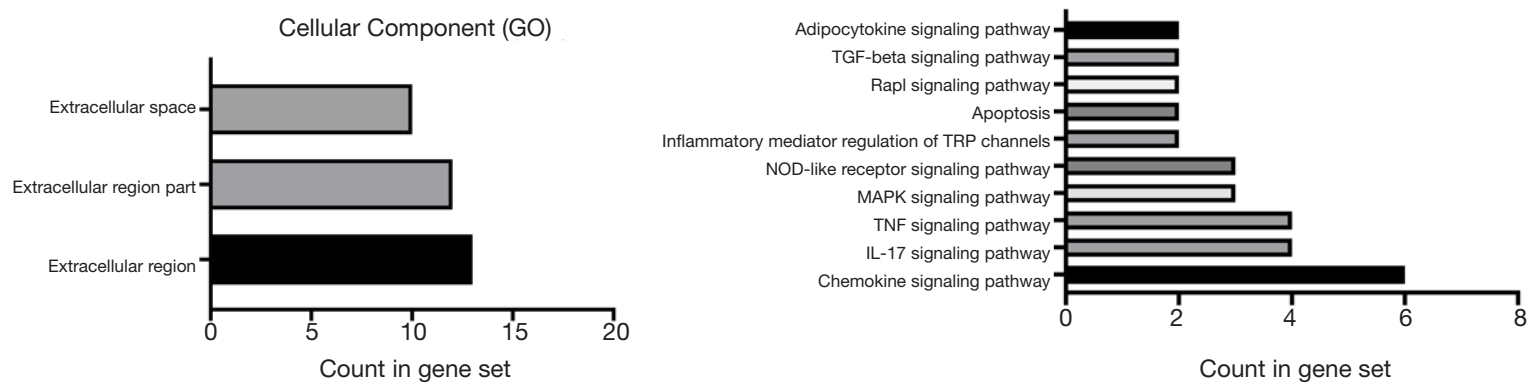

Figure 12 The PPIs, KEGG and GO enrichment analyses of the DEPs in NM group. PPIs, protein-protein interactions; KEGG, Kyoto Encyclopedia of Genes and Genomes; GO, Gene Ontology; DEPs, differentially expressed proteins; NM, nafamostat mesylate. ${ }^{*} \mathrm{P}<0.05$, ${ }^{* *} \mathrm{P}<0.01,{ }^{* * *} \mathrm{P}<0.001$.

of nerve cells (53-55). The JAK-STAT, MAPK, and NODlike receptor signaling pathways are usually involved in inflammatory reactions (56-58). The functions of NTP (neuroprotection and anti-inflammation), and NM (resisting inflammation), in the treatment of SCI have been shown again through pathway analysis.

The immune system is a major contributor to the pathogenesis of spinal cord injury. $\mathrm{T}$ and $\mathrm{B}$ lymphocytes that respond to the same antigen migrate to the spinal cord injury site, resulting in a multifaceted adaptive immune response (59). Lymphocyte's infiltration occurred in the first week after SCI and maintained for a long time. In genetic mice which lack T-cells could find functional and tissue improvement and B-cell knockout mice have improved
BMS scores associated with decreased lesion following SCI (60). This observation may be due to an enhanced regenerative response in the absence of lymphocytes, or a reduction in immune-mediated tissue injury when Tand B-cells are removed. In this study, we found that the number of T cells and B cells were significantly reduced by NTP or NM treatment which demonstrated that they hindered lymphocyte infiltration following SCI.

One of the most common and distressing symptoms suffered by patients with SCI is chronic neuropathic pain (61). Neuropathic pain can occur weeks, months, or years after the trauma, being one of the most significant complications where conventional treatments are mostly ineffective (62). Although BBB score showed that both 


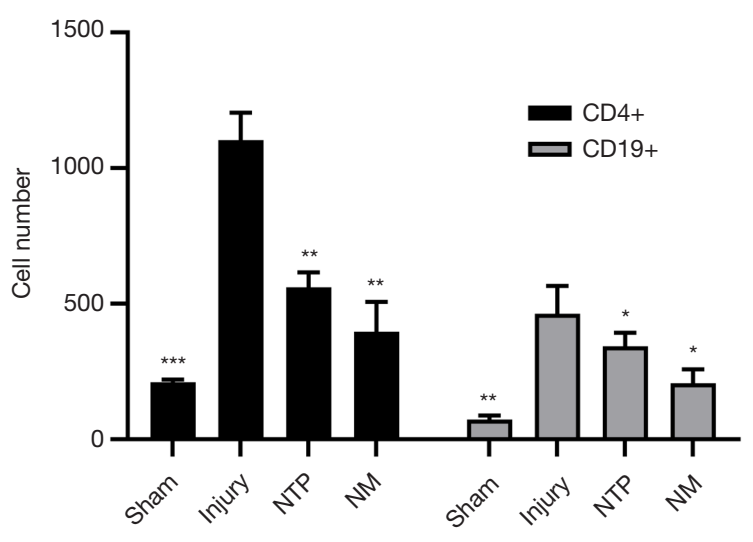

Figure 13 The number of lymphocytes in the center of SCI. ${ }^{*} \mathrm{P}<0.05,{ }^{* *} \mathrm{P}<0.01,{ }^{* *} \mathrm{P}<0.001$.
NTP and NM could significantly improve motor function while only NTP could improve the pathological neuralgia after SCI which indicating that NTP may be better for the treatment of SCI.

The present study demonstrated that regulation of the microenvironment by NTP relied on both its neuroprotective effect and inhibition of inflammation to repair SCI, and the PI3K-Akt, JAK-STAT signaling pathways and apoptosis might also participate in NTP treating SCI. The restoration of SCI with NM was via its antiinflammation effect, and the MAPK and NOD-like receptor signaling pathways might have an important role in the process of NM repairing SCI. Both NTP and NM
A

TNF- $\alpha$

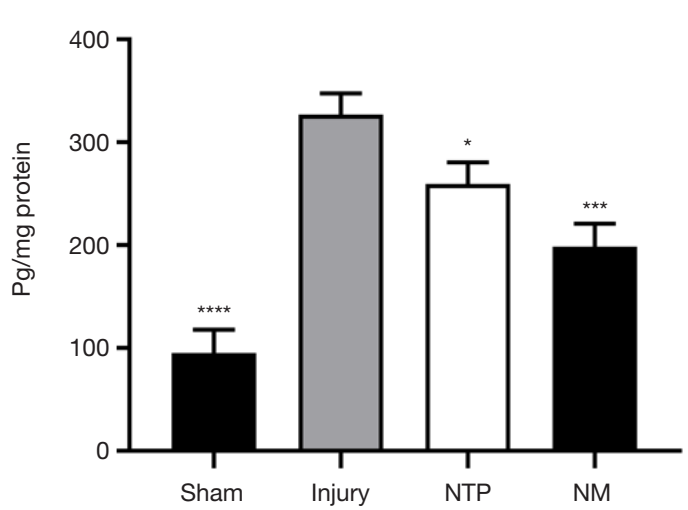

C

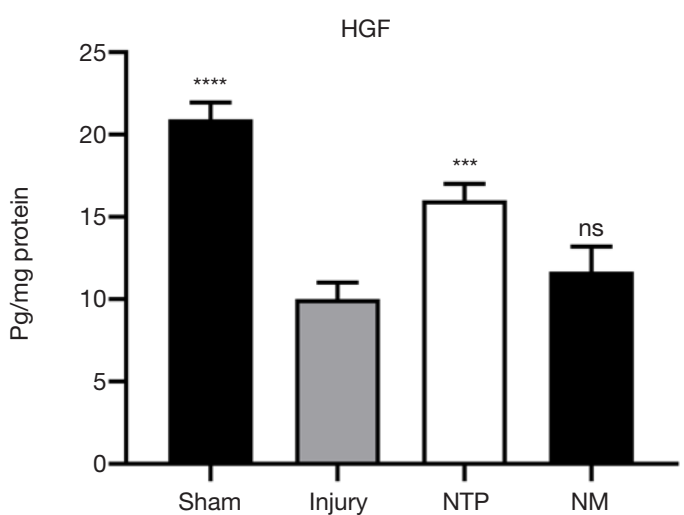

B
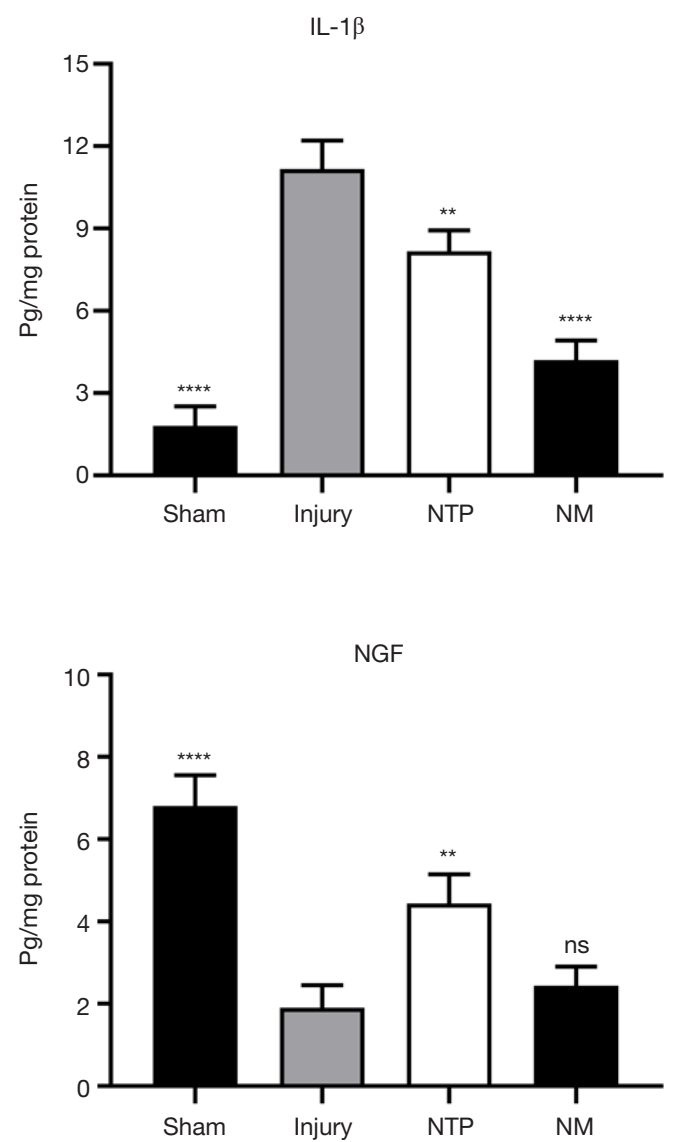

Figure 14 Expressions of TNF- $\alpha$, IL-1 $\beta$, HGF, and NGF after NTP or NM treatment by ELISA. TNF- $\alpha$, tumor necrosis factor-alpha; IL$1 \beta$, interleukin 1 beta; HGF, hepatocyte growth factor; NGF, nerve growth factor; NTP, neurotropin; NM, nafamostat mesylate. ${ }^{*} \mathrm{P}<0.05$, ${ }^{* *} \mathrm{P}<0.01,{ }^{* * *} \mathrm{P}<0.001,{ }^{* * *} \mathrm{P}<0.0001$. 
A

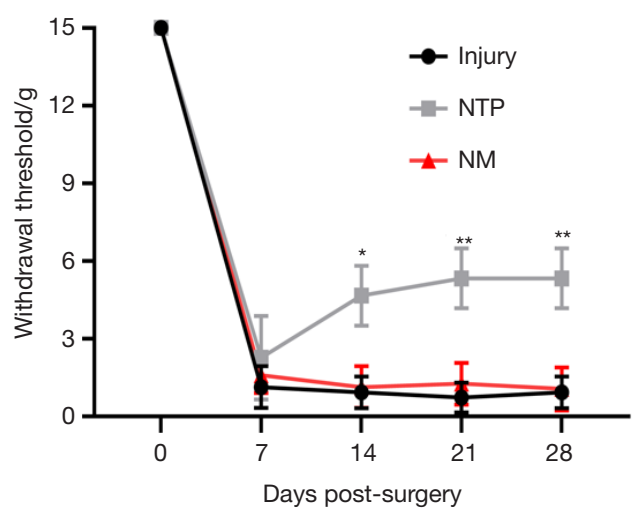

B

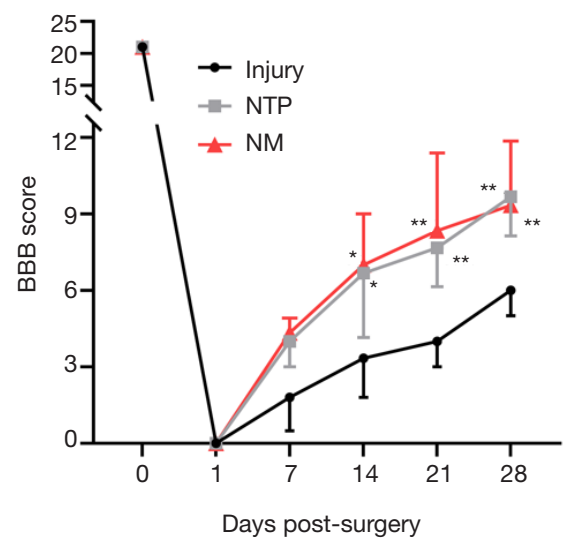

Figure $15 \mathrm{BBB}$ score and withdrawal threshold after NTP or NM treatment. NTP, neurotropin; NM, nafamostat mesylate. ${ }^{*} \mathrm{P}<0.05$, ${ }^{* *} \mathrm{P}<0.01$.

could down-regulate the activation of immune system and improve the functional recovery while only NTP could improve the pathological neuralgia after SCI. As NTP and $\mathrm{NM}$ has been used in clinical work, understanding the effectiveness and mechanism will accelerate its clinical transformation in treating SCI.

\section{Conclusions}

The microenvironment was regulated by NTP via neuroprotection and inhibition of inflammation to repair SCI, and the PI3K-Akt and JAK-STAT signaling pathways might participate in NTP treating SCI. The restoration of SCI by NM was through an antiinflammation effect, and the MAPK and NOD-like receptor signaling pathways might have important roles in the process of NM repairing SCI. This paper determined the molecular mechanisms of these 2 clinical drugs, which revealed their promise for translation as an effective therapy for SCI.

\section{Acknowledgments}

Funding: This study was supported by grants from the National Key Research and Development Project of Stem Cell and Transformation Research (2019YFA0112100), NSFC programs (81620108018, 81930070), Tianjin Key Research and Development Plan, Key Projects for Science and Technology Support (19YFZCSY00660), and Tianjin Research Innovation Project for Postgraduate Students (2019YJSB106).

\section{Footnote}

Reporting Checklist: The authors have completed the ARRIVE reporting checklist. Available at http://dx.doi. org/10.21037atm-21-649

Data Sharing Statement: Available at http://dx.doi. org/10.21037atm-21-649

Conflicts of Interest: All authors have completed the ICMJE uniform disclosure form (available at http://dx.doi. org/10.21037atm-21-649). The authors have no conflicts of interest to declare.

Ethical Statement: The authors are accountable for all aspects of the work in ensuring that questions related to the accuracy or integrity of any part of the work are appropriately investigated and resolved. The experimental processes were approved by the Ethics Committee of Tianjin Institute of Radiation Medicine (IRMDWLL-2019039) and according to the National Institutes of Health in the Guide for the Care and Use of Laboratory Animals (NIH Publications No. 85-23, revised 1996).

Open Access Statement: This is an Open Access article distributed in accordance with the Creative Commons Attribution-NonCommercial-NoDerivs 4.0 International License (CC BY-NC-ND 4.0), which permits the noncommercial replication and distribution of the article with the strict proviso that no changes or edits are made and the 
original work is properly cited (including links to both the formal publication through the relevant DOI and the license). See: https://creativecommons.org/licenses/by-nc-nd/4.0/.

\section{References}

1. Shu J, Cheng F, Gong Z, et al. Transplantation strategies for spinal cord injury based on microenvironment modulation. Curr Stem Cell Res Ther 2020;15:522-30.

2. Huang H, Young W, Skaper S, et al. Clinical Neurorestorative Therapeutic Guidelines for Spinal Cord Injury (IANR/CANR version 2019). J Orthop Translat 2019;20:14-24.

3. Fan B, Wei Z, Yao X, et al. Microenvironment Imbalance of Spinal Cord Injury. Cell Transplant 2018;27:853-66.

4. Norden DM, Faw TD, McKim DB, et al. Bone MarrowDerived Monocytes Drive the Inflammatory Microenvironment in Local and Remote Regions after Thoracic Spinal Cord Injury. J Neurotrauma 2019;36:937-49.

5. Wang Y, Zhang S, Luo M, et al. Hyperbaric oxygen therapy improves local microenvironment after spinal cord injury. Neural Regen Res 2014;9:2182-8.

6. Tian DS, Wang W, Xu YL, et al. Effects of cyclin dependent protein kinase inhibitor olomoucine on the microenvironment of axonal regeneration after spinal cord injury: an experiment with rats. Zhonghua Yi Xue Za Zhi 2006;86:901-5.

7. Suzuki T, Li YH, Mashimo T. The antiallodynic and antihyperalgesic effects of neurotropin in mice with spinal nerve ligation. Anesth Analg 2005;101:793-9, table of contents.

8. Fang WL, Zhao DQ, Wang F, et al. Neurotropin(R) alleviates hippocampal neuron damage through a HIF-1alpha/MAPK pathway. CNS Neurosci Ther 2017;23:428-37.

9. Fang W, Liao W, Zheng $\mathrm{Y}$, et al. Neurotropin reduces memory impairment and neuroinflammation via BDNF/ NF-kappaB in a transgenic mouse model of Alzheimer's disease. Am J Transl Res 2019;11:1541-54.

10. Yao X, Sun C, Fan B, et al. Neurotropin exerts neuroprotective effects after spinal cord injury by inhibiting apoptosis and modulating cytokines. J Orthop Translat 2020;26:74-83.

11. Duan HQ, Wu QL, Yao X, et al. Nafamostat mesilate attenuates inflammation and apoptosis and promotes locomotor recovery after spinal cord injury. CNS Neurosci Ther 2018;24:429-38.

12. Cheriyan T, Ryan DJ, Weinreb JH, et al. Spinal cord injury models: a review. Spinal Cord 2014;52:588-95.
13. Tang H, Guo Y, Zhao Y, et al. Effects and Mechanisms of Acupuncture Combined with Mesenchymal Stem Cell Transplantation on Neural Recovery after Spinal Cord Injury: Progress and Prospects. Neural Plast 2020;2020:8890655.

14. Sami A, Selzer ME, Li S. Advances in the Signaling Pathways Downstream of Glial-Scar Axon Growth Inhibitors. Front Cell Neurosci 2020;14:174.

15. Piri SM, Ghodsi Z, Shool S, et al. Macrophage migration inhibitory factor as a therapeutic target after traumatic spinal cord injury: a systematic review. Eur Spine J 2021. doi: 10.1007/s00586-021-06718-2.

16. Ren Y, Young W. Managing inflammation after spinal cord injury through manipulation of macrophage function. Neural Plast 2013;2013:945034.

17. Zhou X, He X, Ren Y. Function of microglia and macrophages in secondary damage after spinal cord injury. Neural Regen Res 2014;9:1787-95.

18. Zhang Y, Zhou Y, Chen S, et al. Macrophage migration inhibitory factor facilitates prostaglandin E2 production of astrocytes to tune inflammatory milieu following spinal cord injury. J Neuroinflammation 2019;16:85.

19. Huang LJ, Li G, Ding Y, et al. LINGO-1 deficiency promotes nerve regeneration through reduction of cell apoptosis, inflammation, and glial scar after spinal cord injury in mice. Exp Neurol 2019;320:112965.

20. Hong J, Chang A, Zavvarian MM, et al. Level-Specific Differences in Systemic Expression of Pro- and AntiInflammatory Cytokines and Chemokines after Spinal Cord Injury. Int J Mol Sci 2018;19:2167.

21. Harris G, Chen W. Profiling of Cytokine and Chemokine Responses Using Multiplex Bead Array Technology. Methods Mol Biol 2019;2024:79-94.

22. Zhang Y, Lin P, Hong C, et al. Serum cytokine profiles in patients with chronic obstructive pulmonary disease associated pulmonary hypertension identified using protein array. Cytokine 2018;111:342-9.

23. Lin S, Xu C, Lin J, et al. Regulation of inflammatory cytokines for spinal cord injury recovery. Histol Histopathol 2020:18262.

24. Bradbury EJ, Burnside ER. Moving beyond the glial scar for spinal cord repair. Nat Commun 2019;10:3879.

25. Rezvan M, Meknatkhah S, Hassannejad Z, et al. Timedependent microglia and macrophages response after traumatic spinal cord injury in rat: a systematic review. Injury 2020;51:2390-401.

26. Bloom O, Herman PE, Spungen AM. Systemic inflammation in traumatic spinal cord injury. Exp Neurol 
2020;325:113143.

27. Zhu M, Zhou F, Li L, et al. Success with neurotropin in treating pediatric lower extremity pain induced by spinal cord injury after epidural anesthesia. J Pain Res 2017;10:1391-4.

28. Ishikawa T, Yasuda S, Minoda S, et al. Neurotropin((R)) ameliorates chronic pain via induction of brain-derived neurotrophic factor. Cell Mol Neurobiol 2015;35:231-41.

29. Zheng Y, Fang W, Fan S, et al. Neurotropin inhibits neuroinflammation via suppressing NF-kappaB and MAPKs signaling pathways in lipopolysaccharidestimulated BV2 cells. J Pharmacol Sci 2018;136:242-8.

30. Yang J, Qi F, Yao Z. Neonatal Bacillus CalmetteGuérin vaccination alleviates lipopolysaccharide-induced neurobehavioral impairments and neuroinflammation in adult mice. Mol Med Rep 2016;14:1574-86.

31. De Reuck J, Decoo D, Vanderdonckt P, et al. A doubleblind study of neurotropin in patients with acute ischemic stroke. Acta Neurol Scand 1994;89:329-35.

32. Nishimoto S, Okada K, Tanaka H, et al. Neurotropin attenuates local inflammatory response and inhibits demyelination induced by chronic constriction injury of the mouse sciatic nerve. Biologicals 2016;44:206-11.

33. Saleh MR, Muneshige H, Ikuta Y. Effects of neurotropin on hyperalgesia and allodynia in mononeuropathic rats. Life Sci 1998;63:1931-8.

34. Makino S, Egi M, Kita H, et al. Comparison of nafamostat mesilate and unfractionated heparin as anticoagulants during continuous renal replacement therapy. Int J Artif Organs 2016;39:16-21.

35. Hwang SD, Hyun YK, Moon SJ, et al. Nafamostat mesilate for anticoagulation in continuous renal replacement therapy. Int J Artif Organs 2013;36:208-16.

36. Yang JW, Han BG, Kim BR, et al. Superior outcome of nafamostat mesilate as an anticoagulant in patients undergoing maintenance hemodialysis with intracerebral hemorrhage. Ren Fail 2009;31:668-75.

37. Nakano T, Nakamura Y, Irie K, et al. Antithrombin gamma attenuates macrophage/microglial activation and brain damage after transient focal cerebral ischemia in mice. Life Sci 2020;252:117665.

38. Chen T, Wang J, Li C, et al. Nafamostat mesilate attenuates neuronal damage in a rat model of transient focal cerebral ischemia through thrombin inhibition. Sci Rep 2014;4:5531.

39. Wang X, Tang Y, Shen R, et al. Hepatocyte growth factor (HGF) optimizes oral traumatic ulcer healing of mice by reducing inflammation. Cytokine 2017;99:275-80.
40. Pang Y, Liang MT, Gong Y, et al. HGF Reduces Disease Severity and Inflammation by Attenuating the NFkappaB Signaling in a Rat Model of Pulmonary Artery Hypertension. Inflammation 2018;41:924-31.

41. Takano M, Kawabata S, Shibata S, et al. Enhanced Functional Recovery from Spinal Cord Injury in Aged Mice after Stem Cell Transplantation through HGF Induction. Stem Cell Reports 2017;8:509-18.

42. Stelmashook EV, Genrikhs EE, Novikova SV, et al. Behavioral effect of dipeptide NGF mimetic GK-2 in an in vivo model of rat traumatic brain injury and its neuroprotective and regenerative properties in vitro. Int J Neurosci 2015;125:375-9.

43. Gerling N, Culmsee C, Klumpp S, et al. The tyrosine phosphatase inhibitor orthovanadate mimics NGFinduced neuroprotective signaling in rat hippocampal neurons. Neurochem Int 2004;44:505-20.

44. Lu J, Frerich JM, Turtzo LC, et al. Histone deacetylase inhibitors are neuroprotective and preserve NGFmediated cell survival following traumatic brain injury. Proc Natl Acad Sci U S A 2013;110:10747-52.

45. Tankó LB, Goldhahn J, Varela A, et al. Does Activin Receptor Blockade by Bimagrumab (BYM338) Pose Detrimental Effects on Bone Healing in a Rat Fibula Osteotomy Model? Calcif Tissue Int 2016;99:310-21.

46. Brackmann FA, Alzheimer C, Trollmann R. Activin A in perinatal brain injury. Neuropediatrics 2015;46:82-7.

47. Su X, Huang L, Xiao D, et al. Research Progress on the Role and Mechanism of Action of Activin A in Brain Injury. Front Neurosci 2018;12:697.

48. Prakash S, Rai U, Kosuru R, et al. Amelioration of diet-induced metabolic syndrome and fatty liver with sitagliptin via regulation of adipose tissue inflammation and hepatic Adiponectin/AMPK levels in mice. Biochimie 2020;168:198-209.

49. Lee WJ, Ahn HM, Roh H, et al. Decorin-expressing adenovirus decreases collagen synthesis and upregulates MMP expression in keloid fibroblasts and keloid spheroids. Exp Dermatol 2015;24:591-7.

50. Vestergaard C, Johansen C, Otkjaer K, et al. Tumor necrosis factor-alpha-induced CTACK/CCL27 (cutaneous T-cell-attracting chemokine) production in keratinocytes is controlled by nuclear factor kappaB. Cytokine 2005;29:49-55.

51. MacLean M, Derk J, Ruiz HH, et al. The Receptor for Advanced Glycation End Products (RAGE) and DIAPH1: Implications for vascular and neuroinflammatory dysfunction in disorders of the central nervous system. 
Neurochem Int 2019;126:154-64.

52. Wang $\mathrm{H}$, Zhao Z, Liu C, et al. Receptor for Advanced Glycation End-Products (RAGE) Blockade Do Damage to Neuronal Survival via Disrupting Wnt/beta-Catenin Signaling in Spinal Cord Injury. Neurochem Res 2018;43:1405-12.

53. Tang J, Guo WC, Hu JF, et al. Let-7 participates in the regulation of inflammatory response in spinal cord injury through PI3K/Akt signaling pathway. Eur Rev Med Pharmacol Sci 2019;23:6767-73.

54. Qi L, Jiang-Hua M, Ge-Liang H, et al. MiR-34a Inhibits Spinal Cord Injury and Blocks Spinal Cord Neuron Apoptosis by Activating Phatidylinositol 3-kinase (PI3K)/ AKT Pathway Through Targeting CD47. Curr Neurovasc Res 2019;16:373-81.

55. Li Y, Guo Y, Fan Y, et al. Melatonin Enhances Autophagy and Reduces Apoptosis to Promote Locomotor Recovery in Spinal Cord Injury via the PI3K/AKT/mTOR Signaling Pathway. Neurochem Res 2019;44:2007-19.

56. Ning SL, Zhu H, Shao J, et al. MiR-21 inhibitor improves locomotor function recovery by inhibiting IL-6R/JAKSTAT pathway-mediated inflammation after spinal cord injury in model of rat. Eur Rev Med Pharmacol Sci 2019;23:433-40.

Cite this article as: Sun $\mathrm{C}, \mathrm{Li} \mathrm{B}$, Duan $\mathrm{H}$, Tao B, Zhao X, Li W, Pang Y, Fan B, Feng S. Cytokine expressions of spinal cord injury treated by neurotropin and nafamostat mesylate. Ann Transl Med 2021;9(6):489. doi: 10.21037/atm-21-649
57. Qian Z, Chang J, Jiang F, et al. Excess administration of miR-340-5p ameliorates spinal cord injury-induced neuroinflammation and apoptosis by modulating the P38MAPK signaling pathway. Brain Behav Immun 2020.

58. Zhai J, Tao L, Zhang S, et al. Calycosin ameliorates doxorubicin-induced cardiotoxicity by suppressing oxidative stress and inflammation via the sirtuin 1-NOD-like receptor protein 3 pathway. Phytother Res 2020;34:649-59.

59. Jones TB. Lymphocytes and autoimmunity after spinal cord injury. Exp Neurol 2014;258:78-90.

60. Tanabe S, Yamashita T. B lymphocytes: Crucial contributors to brain development and neurological diseases. Neurosci Res 2019;139:37-41.

61. Batista CM, Mariano ED, Onuchic F, et al. Characterization of traumatic spinal cord injury model in relation to neuropathic pain in the rat. Somatosens Mot Res 2019;36:14-23.

62. Wang Y, Zhao Y, Ma X, et al. Beneficial Effects of Electroacupuncture on Neuropathic Pain Evoked by Spinal Cord Injury and Involvement of PI3K-mTOR Mechanisms. Biol Res Nurs 2019;21:5-13.

(English Language Editor: J. Jones) 